\title{
Action plans in asthma
}

\author{
Marie-France Beauchesne PharmD ${ }^{1,2}$, Valérie Levert ${ }^{2}$, Miray El Tawil ${ }^{2}$, \\ Manon Labrecque MD MSc FRCP ${ }^{1,3}$, Lucie Blais $\mathrm{PhD}^{1,2}$
}

\begin{abstract}
M-F Beauchesne, V Levert, M El Tawil, M Labrecque, L Blais. Action plans in asthma. Can Respir J 2006;13(6):306-310.
\end{abstract}

BACKGROUND: Action plans are recommended for most patients with persistent asthma to reduce the morbidity associated with this chronic disease. Unfortunately, despite these recommendations, this tool remains underused.

METHODS: The authors conducted a descriptive study at the asthma clinic of a tertiary care centre to determine the number of asthmatic patients presenting to a respiratory physician (new reference or follow-up visit) who possessed an individualized, written action plan, and to evaluate the patients' level of confidence and perceived efficacy toward their plans. In addition, for all patients in the study, the level of confidence in and the perceived efficacy of three different action plans (two traditional tools versus a simplified tool) were compared. RESULTS: A total of 92 asthmatic patients were included in the study. Overall, $46 \%$ of the patients possessed an action plan. The patients' average level of confidence and perceived efficacy toward their action plans were high (4.1 out of five and 3.3 out of four, respectively). When the three different action plans were compared, the level of confidence in and perceived efficacy of the traditional tools were similar, both being superior to the simplified tool.

CONCLUSION: The number of asthmatic patients who presented to the asthma clinic and who possessed an action plan was higher than the reported Canadian mean of $10 \%$; however, most of the patients were treated by specialized respiratory physicians, which may explain this improvement. Considering that most patients with persistent asthma should have an individualized, written action plan, the present study confirms that this tool is still not used for all asthmatic patients.

Key Words: Action plans for asthma; Asthma; Asthma education

\section{Plans d'action et asthme}

HISTORIQUE : Un plan d'action est recommandé pour la plupart des patients qui souffrent d'un asthme persistant afin de réduire la morbidité associée à cette maladie chronique. Malheureusement, malgré les recommandations en ce sens, cet outil reste sous-utilisé.

MÉTHODES : Les auteurs ont réalisé une étude descriptive à la clinique de traitement de l'asthme d'un centre de soins tertiaires afin de déterminer combien d'asthmatiques qui consultent un pneumologue (consultation nouvelle ou visite de suivi) possèdent un plan d'action individualisé écrit et afin d'évaluer le degré de confiance des patients à l'endroit de leur plan d'action et leur perception de son efficacité. De plus, on a demandé à tous les patients inscrits à l'étude de comparer leur degré de confiance à l'endroit de trois plans d'action différents (deux classiques, un simplifié) et leur perception de leur efficacité.

RÉSULTATS : En tout, 92 patients asthmatiques ont été inscrits à cette étude. Dans l'ensemble, $46 \%$ des patients possédaient un plan d'action. Le degré de confiance moyen des patients à l'endroit de leur plan d'action et son efficacité perçue étaient élevés (soit 4,1 sur 5 et 3,3 sur 4, respectivement). Lorsque les trois plans d'action différents ont été comparés, le degré de confiance à l'endroit des outils classiques et leur efficacité perçue se sont révélés semblables et tous deux supérieurs comparativement à l'outil simplifié.

CONCLUSION : Le nombre de patients asthmatiques se présentant à la clinique de traitement de l'asthme en possession d'un plan d'action était plus élevé que la moyenne canadienne rapportée, qui se situe à $10 \%$. Par contre, la plupart des patients étaient traités par des pneumologues spécialistes, ce qui pourrait expliquer cette statistique. Compte tenu que la plupart des patients souffrant d'un asthme persistant devraient avoir en leur possession un plan d'action individualisé écrit, la présente étude confirme que cet outil n'est toujours pas utilisé par tous les patients asthmatiques.

A sthma is a chronic disease that affects more than $8 \%$ of the Canadian population aged 12 years or older (1). The global costs of this disease were estimated to be greater than $\$ 600$ million in 1990 (2). Furthermore, approximately 28\% of asthmatic patients visited the emergency department (ED) in Canada in 1999 (3). Educational programs on asthma that include individualized, written action plans, compared with those that do not, have been shown to be superior in reducing the morbidity associated with asthma (4). In addition, it has been shown that the rate of deaths is lower in asthmatic patients who possess an action plan (5). Therefore, to prevent the worsening of asthma leading to the use of health care services, action plans are recommended for the majority of patients who have moderate to severe asthma or who have a history of severe exacerbations $(6,7)$.

When provided in the context of a structured educational intervention, an action plan is a key element in the care of patients with asthma. Unfortunately, the use of this tool is suboptimal. In fact, approximately two-thirds of asthmatic patients hesitate to modify their treatment when an exacerbation occurs (8). In addition, according to a Canadian survey conducted between 1996 and 1997, a low proportion of asthmatic patients (10\%) received an action plan, and only $17 \%$ of physicians reported that they gave written action plans to all or most of their asthmatic patients (8).

In a meta-analysis (9), action plans that included two or three criteria of application were found to be as efficacious as those that had four criteria. This finding could be explained by the fact that action plans that include many criteria are not only more precise but also more complex, which could limit

${ }^{1}$ Hôpital du Sacré-Coeur de Montréal; ${ }^{2}$ Faculty of Pharmacy; ${ }^{3}$ Faculty of Medicine, University of Montreal, Montreal, Quebec

Correspondence: Dr Marie-France Beauchesne, Pharmacy, Hôpital du Sacré-Coeur de Montréal, 5400 Gouin Boulevard West, Montreal,

Quebec H4J 1C5. Telephone 514-338-2222 ext 2666, fax 514-338-3200, e-mail marie-france.beauchesne@umontreal.ca 
their comprehension by patients with asthma. Therefore, a simplified action plan may be as efficacious and simpler for the patient to use, while promoting adherence to the tool (10). We conducted a study to describe the use of action plans by asthmatic patients and to evaluate the patients' level of confidence in and perceived efficacy of different models of action plans.

\section{METHODS}

The present descriptive study was conducted at l'Hôpital du Sacré-Cour de Montréal, a tertiary care centre affiliated with the University of Montreal (Montreal, Quebec). The study was approved by the institutional ethics committee and participants provided written informed consent. Patients were recruited at the outpatient asthma clinic by two pharmacy students under the supervision of a certified asthma educator over a period of 17 weeks from May 3 to August 27, 2004. Patients who were included were 18 to 75 years of age, had a diagnosis of asthma based on the criteria of spirometry measurements described in the Canadian guidelines (6), and spoke French or English. Patients who had a diagnosis of chronic obstructive pulmonary disease were excluded.

A number of clinics were scheduled during the study period. In the morning of each of these clinics, the pharmacy student received a list of all scheduled patients. Every available chart was reviewed for a preselection of patients based on inclusion and exclusion criteria (ie, asthma diagnosis based on spirometry criteria written by a pulmonary physician on the patient's chart, 18 to 75 years of age and no diagnosis of chronic obstructive pulmonary disease). For the patients who did not have a chart available, the diagnosis of asthma was confirmed after visiting with a pulmonary physician. Every patient who came to the clinic and met the inclusion criteria was asked by the pharmacy student to take part in the study. Both new patients and patients already followed at the clinic were included. Patients who visited the outpatient asthma clinic at l'Hôpital du Sacré-Cour de Montréal were seen by respiratory physicians only.

The present study had the following goals: to determine the number of patients who possessed an action plan; to assess the level of confidence in and the perceived efficacy of this tool; and to compare the level of confidence in and the perceived efficacy of a simplified action plan versus two traditional tools that included many application criteria.

All data in the present study were collected from an interview between the pharmacy student and the patient. Three questionnaires were completed, one after another, during the interview to collect all data, except for the prebronchodilator forced expiratory volume in $1 \mathrm{~s}$, which was collected from the medical chart of the patient. The questionnaires for the present study were developed in the English and French languages, and were tested beforehand by asthmatic patients to ensure the clarity of the questions.

The first questionnaire was used to collect the following information from patients: age, sex, ethnicity, whether their asthma was followed by a respiratory physician or general practitioner, current occupation, level of education, smoking status, number of years since the diagnosis of asthma, prebronchodilator forced expiratory volume in $1 \mathrm{~s}$, current regular medication for asthma, whether asthma education was received in the past, use of health care services for asthma in the past year (eg, ED visit, hospitalization and unscheduled visit to a doctor), absenteeism in the past year from work or school because of asthma (yes or no) and prescription of oral corticosteroids received in the past year (yes or no).

The second questionnaire was used to collect the following information from patients: whether they possessed an individualized, written action plan, and if so, whether the action plan had been applied at least once; their level of confidence in the action plan in possession on a scale of one to five (where five is the highest level of confidence); and the perceived efficacy associated with the use of the plan on a scale of one to four (where four is the highest level of perceived efficacy).

The third and last questionnaire included seven questions. Patients were asked to read three different action plans and rate their level of confidence in (scale of one to five, where five is the highest level) and perceived efficacy of (scale of one to four, where four is the highest level) each action plan (a total of six questions [ie, two identical questions for each action plan]). The last question asked about the preferred model of action plan (among the three presented). All questionnaires and scales used were developed for use in the present study in the French and English languages, and are not validated.

The three actions plans that were compared were a simplified plan and two traditional plans based on seven criteria, which were based on the goals defined in the Canadian asthma guidelines $(11,12)$. The traditional action plans indicate to patients to increase their usual dose of inhaled corticosteroid (ICS) or to add another therapy (such as an oral corticosteroid) in the following situations: the beginning of a respiratory tract infection; daytime symptoms more than four times per week; night-time symptoms more than once per week; worsening of asthma following exposure to a triggering factor; the use of rescue medication more than four times per week (excluding use before exercise); limitation in daytime (or usual) activities because of asthma; and reduction in peak flow measurements. The plan was individualized by clinicians, who marked the situations in which the patient should modify his or her therapy and how to modify the treatment (eg, double versus quadruple the dose of ICS). The third action plan was a simplified tool based on only one key message. The simplified action plan indicated to quadruple the dose of the prescribed ICS for 14 days in the event of an increased use of the prescribed short-acting beta-agonist (versus the usual use) for daytime or night-time symptoms of asthma for two days or longer. Canadian asthma guidelines recommend rapidly managing asthma exacerbations by a two- to fourfold increase in the regular ICS dose for at least 14 days (6). However, little is known on the optimal dose and duration of treatment with the ICS in this situation. Two randomized controlled trials failed to show the efficacy of doubling the dose of ICS when asthma began to worsen $(13,14)$, whereas quadrupling the dose appeared to have a beneficial effect (15). This is why it was decided to indicate, in the simplified tool, to quadruple the dose of ICS when the asthma worsened. However, more evidence is needed on the best approach (ie, optimal dose of ICS and duration of increased therapy) to use in action plans. Both the simplified and traditional tools indicate to seek urgent medical care in case of significant worsening or deterioration of the asthma.

Statistical analyses were performed using Excel (Microsoft Corporation, USA) and SPSS (version 11.5, SPSS Inc, USA). Descriptive statistics (means and proportions) are reported to describe the baseline characteristics of the patients. The percentages of asthmatic patients who possessed and applied an individualized, written action plan at least once, who received asthma education, and who attended an asthma education centre were determined. The percentages of patients who visited the ED, who were hospitalized, who had an unscheduled visit to a doctor and who took oral corticosteroids because of their asthma in the year preceding the interview were all assessed. For patients who experienced these events, the percentage of patients who possessed a written action plan was calculated. The average level of confidence in and the perceived efficacy of the different action plans (the one that 


\section{TABLE 1}

Baseline characteristics of the study patients $(n=92)$

\begin{tabular}{lc}
\hline Characteristic & \\
\hline Female, $\mathrm{n}(\%)$ & $59(64.1)$ \\
Age, mean years $\pm \mathrm{SD}$ & $52 \pm 13.3$ \\
Asthma followed by a: & \\
$\quad$ Respiratory physician, $\mathrm{n}(\%)$ & $83(90.2)$ \\
$\quad$ General practitioner, $\mathrm{n}(\%)$ & $9(9.8)$ \\
Occupation, $\mathrm{n}(\%)$ & \\
Worker & $2(2.2)$ \\
Student & $18(19.6)$ \\
Unemployed & $18(19.6)$ \\
Retired & $22(23.9)$ \\
Level of education, $\mathrm{n}(\%)$ & \\
Elementary school & $18(19.6)$ \\
High school & $39(42.4)$ \\
College or university & $33(35.9)$ \\
Data not available & $2(2.2)$ \\
Current smoker, $\mathrm{n}(\%)$ & $10(10.9)$ \\
Number of years since the diagnosis of asthma, mean $\pm \mathrm{SD}$ & $19.9 \pm 14.8$ \\
Prebronchodilator FEV $(\mathrm{L})$, mean \pm SD & $2.17 \pm 0.83$ \\
Current regular medication for asthma & \\
Short-acting beta-2-agonist, $\mathrm{n}(\%)$ & $78(84.8)$ \\
Long-acting beta-2-agonist, $\mathrm{n}(\%)$ & $63(68.5)$ \\
Short-acting anticholinergic, $\mathrm{n}(\%)$ & $10(10.9)$ \\
Inhaled corticosteroids, $\mathrm{n}(\%)$ & $798(85.9)$ \\
$\quad$ Mean dose \pm SD, $\mu \mathrm{Cg}(\mathrm{CFC}-\mathrm{BDP}$ equivalent) & $650 \pm 640$ \\
Oral corticosteroids (at the time of visit), $\mathrm{n}(\%)$ & $14(15.2)$ \\
Theophylline, $\mathrm{n}(\%)$ & $7(7.6)$ \\
Antileukotrienes, $\mathrm{n}(\%)$ & $13(14.1)$ \\
\hline
\end{tabular}

CFC-BDP Chlorofluorocarbon-beclomethasone dipropionate; FEV 1 Forced expiratory volume in $1 \mathrm{~s}$

the patient possessed and the three different models) were estimated. The percentage of patients who had a preference for each of the three different models of action plan presented during the interview was determined. Finally, the correlations between some of the baseline characteristics of the patients (eg, level of education, number of years since the diagnosis of asthma, previous exacerbations and asthma education) were tested using the $\chi^{2}$ and Fisher exact tests to identify patient characteristics associated with the possession of an action plan, the application of their action plan, and a higher level of confidence and perceived efficacy toward their tool.

\section{RESULTS}

A total of 140 patients were scheduled to visit the asthma clinic on the days of recruitment and met the inclusion criteria. From that number, 114 visited the asthma clinic (26 patients did not present to the clinic) and were invited to participate in the study. A total of 16 patients refused, and thus, 92 patients were included in the present study. The baseline characteristics of the patients are presented in Table 1. Sixty-four per cent of the patients were female, and the mean age was 52 years. Most participants were Caucasian (80\%). The large majority of patients were followed by a respiratory physician for their asthma (90\%), 54\% were working and $42 \%$ had a high school degree as their highest level of education. A total of 63 patients $(68.5 \%)$ were prescribed a long-acting beta-2-agonist and the mean dose of ICS was $650 \pm 640 \mu \mathrm{g} /$ day (chlorofluorocarbonbeclomethasone dipropionate equivalent), meaning that most patients had at least moderate asthma if treated as described in the Canadian asthma guidelines (6).

The main results are presented in Table 2 . A total of 40 patients $(44 \%)$ mentioned that they had received previous asthma education (provided by an asthma educator at the asthma clinic), and 42 (46\%) possessed an individualized, written action plan. The use of health care services and the possession of an action plan are contrasted in Table 2. In general, there was a similar number of patients who used health care services in the year preceding the interview and who did not possess an action plan compared with the number of patients who used health care services and who possessed an individualized, written action plan; however, no statistical analyses were performed to compare the groups. For example, 24\% of the patients who had an action plan (10 of 42 ) visited the ED, whereas $28 \%$ of those who did not have an action plan (14 of 50) visited the ED. From the 42 patients who had an action plan, $83 \%$ reported applying the tool at least once since it had been given to them. The patients' average level of confidence (4.1 out of five) and perceived efficacy (3.3 out of four) toward their actions plans were high.

When patients were asked to compare their level of confidence in and their perceived efficacy of the three different action plans, the two traditional tools were rated as equivalent, both being superior to the simplified action plan (Table 3). No correlations were found between baseline characteristics of the patients and the possession of, application of, level of confidence in and perceived efficacy of the action plan. In addition, the application of the action plan at least once did not influence the level of confidence nor the perceived efficacy in patients who possessed this tool.

\section{DISCUSSION}

The results of the present study demonstrate that not all asthmatic patients (only 46\%) who present to an asthma clinic for a visit with a respiratory physician possess an individualized, written action plan. However, this result is far superior to the $10 \%$ reported in a Canadian survey (8). This difference may be explained by the fact that most of the patients (90\%) were followed by a respiratory physician for their asthma. In determining the prevalence of possessing an action plan, we did not distinguish between new patients and patients who were already followed at the clinic, and we did not collect data on the number of follow-up visits in the year preceding the interview. Therefore, if we assume that it is more likely for patients who have regular follow-up visits to their respiratory physician to possess an action plan, this may also explain why our result (46\%) is higher than that previously reported $(10 \%)$. Most of the patients who possessed an action plan (40 of $42[95 \%]$ ) had received some form of asthma education, but only 44\% (40 of 92) of all patients (those who had and did not have an action plan) had visited an asthma education centre in the past.

Many patients had required the use of health care services in the previous year for asthma, and only a few of them had an action plan. For example, only $42 \%$ of the patients (10 of 24 ) who had visited the ED in the previous year had an action plan. This finding highlights the importance of promoting the use of action plans to prevent the morbidity associated with asthma. The present study was not designed to evaluate the impact of action plans on the use of health care services, but a similar number of patients who did not possess an action plan used health care services compared with those who possessed an individualized, written action plan; however, no statistical 
TABLE 2

Use of an action plan and health care services in the previous year

\begin{tabular}{|c|c|c|c|}
\hline & $\begin{array}{l}\text { All patients } \\
\quad(n=92)\end{array}$ & $\begin{array}{l}\text { Patients with an } \\
\text { action plan }(n=42)\end{array}$ & $\begin{array}{c}\text { Patients without } \\
\text { an action plan }(n=50)\end{array}$ \\
\hline Patients who received asthma education, $\mathrm{n}(\%)$ & $40(43.5)$ & $40(95.2)$ & - \\
\hline Patients who applied their action plan at least once, $\mathrm{n}(\%)$ & - & $35(83.3)$ & - \\
\hline Patients who presented to the emergency department for asthma in the past year, $\mathrm{n}(\%)$ & $24(26.1)$ & 10 & 14 \\
\hline Patients who were hospitalized for asthma in the past year, $\mathrm{n}(\%)$ & $15(16.3)$ & 7 & 8 \\
\hline Patients who had an unscheduled visit to a doctor for asthma in the past year, $\mathrm{n}(\%)$ & $19(20.7)$ & 8 & 11 \\
\hline Patients who took a short course of oral corticosteroids in the past year, $\mathrm{n}(\%)$ & $53(57.6)^{*}$ & 26 & 27 \\
\hline Patients who missed work or school because of asthma in the past year, $\mathrm{n}(\%)$ & $22(23.9)$ & 10 & 12 \\
\hline Level of confidence of the patients toward their action plan, mean $\pm \mathrm{SD}$ (out of 5 ) & - & $4.1 \pm 0.8$ & - \\
\hline Level of perceived efficacy of the patients toward their action plan, mean \pm SD (out of 4 ) & - & $3.3 \pm 0.7$ & - \\
\hline
\end{tabular}

*Thirteen patients took a short course of oral corticosteroids according to their action plan

\section{TABLE 3}

Comparison of the three different action plans $(n=92)$

\begin{tabular}{lccc}
\hline & Traditional action plan 1 & Traditional action plan 2 & Simplified action plan 3 \\
\hline Level of confidence, mean \pm SD (out of 5) & $3.8 \pm 1.0$ & $3.9 \pm 1.1$ & $3.3 \pm 1.1$ \\
Level of perceived efficacy, mean \pm SD (out of 4) & $3.3 \pm 0.7$ & $3.3 \pm 0.7$ & $3.0 \pm 0.8$ \\
Preference for an action plan, $\mathrm{n}(\%)^{*}$ & $25(27.2)$ & $29(31.5)$ & $11(12.0)$
\end{tabular}

$P>0.05$ for all comparisons of action plan 1 versus action plan 2. P<0.05 for comparisons of action plan 1 versus action plan 3 , and action plan 2 versus action plan 3. ${ }^{*}$ Twenty-seven patients (29.3\%) did not have any preference for one action plan over the others

analyses were performed on these results. It would also have been interesting to characterize the level of asthma control, the need for rescue medication and the quality of life of the patients; however, because the present study was not designed to evaluate the efficacy of action plans in asthma but to describe the possession of this tool, these data were not collected.

In patients who had an action plan, the majority (83\%) had applied the tool at least once. In fact, they had a high level of confidence (4.1 out of five) and perceived efficacy (3.3 out of four) toward their action plan. To reduce potential bias caused by the 'desire to please' health care providers, the interviews were conducted by a pharmacy student not involved in the care of the patient, and results were kept confidential. We also performed a comparison of three different action plans: two traditional ones with seven application criteria, and a simplified tool based on only one key message.

Surprisingly, the two traditional action plans were perceived as similar in terms of level of confidence and perceived efficacy, but better than the simplified tool. This finding could be explained by the fact that patients associate complexity with efficacy. The result could have been different if patients were actually asked to apply the different action plans. When patients were asked their preference among the three action plans, the simplified tool was the one least frequently identified. The fact that the simplified tool indicated to automatically quadruple the dose of their ICS, whereas the traditional tools did not specify the amount of increase in the usual dose of ICS required (must be written by a clinician), may have been a barrier to the evaluation of this tool because of the fear of side effects from ICS. Furthermore, 27 patients (29\%) did not have a preference for one action plan over the other models.

We did not collect information on baseline characteristics of the patients who refused to participate $(n=16)$ and who did not attend the clinic $(n=26)$ because we could not complete the first questionnaire to collect these data, and this was a potential bias in the study. No correlation was found between different baseline patient characteristics and the different outcomes measured, but the sample size in our study was small. Our study had other limitations, such as the use of nonvalidated questionnaires. In addition, patient recruitment in an asthma clinic run by respiratory physicians limits the extrapolation of our results to other patients who have different levels of disease severity and who are followed by general practitioners for their asthma. The generalizability of the results to a primary care setting is also uncertain due to the fact that the use of a detailed action plan is limited by access to education resources, and a simpler tool may be more convenient in this context. However, the present study provides up-to-date information on the use of action plans in asthma. It would now be interesting to conduct a trial comparing the efficacy of different models (including a simplified version) of action plans in patients who have never received and used such a tool.

\section{CONCLUSIONS}

The present study demonstrates that there is still an insufficient number of asthmatic patients who possess an action plan. It also suggests that a simplified tool would not necessarily be more widely used than the traditional action plans currently available. Further prospective trials are required to evaluate the optimal use of action plans in asthma.

ACKNOWLEDGEMENTS: Drs Marie-France Beauchesne and Lucie Blais are Endowment Pharmaceutical Co-Chairs of AstraZeneca in Respiratory Health. Lucie Blais is a recipient of a New Investigator grant from the Canadian Institutes of Health Research. The authors have received a grant from the Apotex/PACE program and the Canadian Institutes of Health Research (summer research fund for pharmacy students) for this study, which originated at l'Hôpital du Sacré-Cœur de Montréal. 


\section{REFERENCES}

1. Statistiques Canada. Asthme, selon le sexe, population à domicile de 12 ans et plus, Canada, provinces, territoires, régions sociosanitaires et groupes de régions homologues, 2000-2001. <http://www.statcan.ca/francais/freepub/82-221-XIF/00604/tables/ pdf/1256_f.pdf> (Version current at August 14, 2006).

2. Krahn MD, Berka C, Langlois P, Detsky AS. Direct and indirect costs of asthma in Canada, 1990. CMAJ 1996;154:821-31.

3. Chapman KR, Ernst P, Grenville A, Dewland P, Zimmerman S. Control of asthma in Canada: Failure to achieve guideline targets. Can Respir J 2001;8(Suppl A):35A-40A.

4. Gibson PG, Powell H, Coughlan J, et al. Self-management education and regular practitioner review for adults with asthma. Cochrane Database Syst Rev 2003:CD001117.

5. Abramson MJ, Bailey MJ, Couper FJ, et al; Victorian Asthma Mortality Study Group. Are asthma medications and management related to deaths from asthma? Am J Respir Crit Care Med 2001;163:12-8.

6. Boulet LP, Becker A, Bérubé D, Beveridge R, Ernst P. Canadian Asthma Consensus Report, 1999. Canadian Asthma Consensus Group. CMAJ 1999;161(Suppl 11):S1-S61.

7. National Asthma Education and Prevention Program. Expert Panel Report: Guidelines for the Diagnosis and Management of Asthma Update on Selected Topics - 2002. Monitoring. J Allergy Clin Immunol 2002;110(Suppl 5):S183-S96.

8. Groupe de travail national sur la lutte contre l'asthme. Prévention et prise en charge de l'asthme au Canada (2000). <http://www.phac-aspc.gc.ca/publicat/pma-pca00/index_f.html> (Version current at August 14, 2006).

9. Gibson PG, Powell H. Written action plans for asthma: An evidence-based review of the key components. Thorax 2004;59:94-9.

10. Mellins RB, Evans D, Zimmerman B, Clark NM. Patient compliance. Are we wasting our time and don't know it? Am Rev Respir Dis 1992;146:1376-7.

11. Comite de revue de l'utilisation des medicaments. Action plan for persons with asthma. <http://www.cdm.gouv.qc.ca> (Version current at August 14, 2006).

12. Boutin H, Robichaud P, Boulet LP. Asthme : Plan d'action - Format "Frigo". Programme d'enseignement sur l'asthme, Hôpital Laval, 2001. <www.asthme-quebec.ca/ressources/materiel_utile.html> (Version current at August 14, 2006).

13. Harrison TW, Oborne J, Newton S, Tattersfield AE. Doubling the dose of inhaled corticosteroid to prevent asthma exacerbations: Randomised controlled trial. Lancet 2004;363:271-5.

14. FitzGerald JM, Becker A, Sears MR, Mink S, Chung K, Lee J; Canadian Asthma Exacerbation Study Group. Doubling the dose of budesonide versus maintenance treatment in asthma exacerbations. Thorax 2004;59:550-6.

15. Foresi A, Morelli MC, Catena E. Low-dose budesonide with the addition of an increased dose during exacerbations is effective in long-term asthma control. On behalf of the Italian Study Group. Chest 2000;117:440-6. 


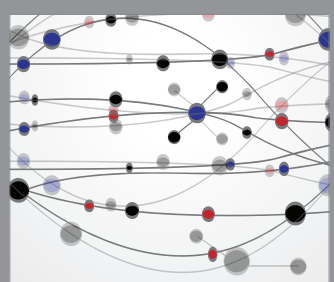

The Scientific World Journal
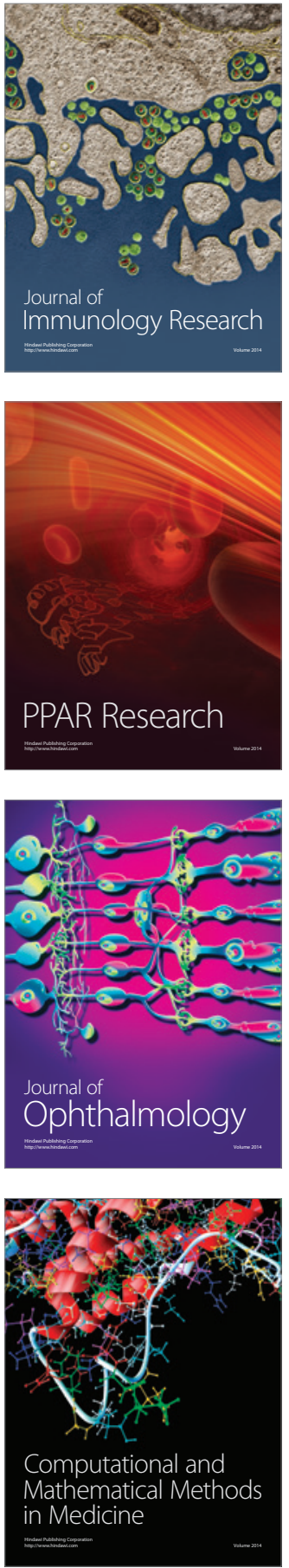

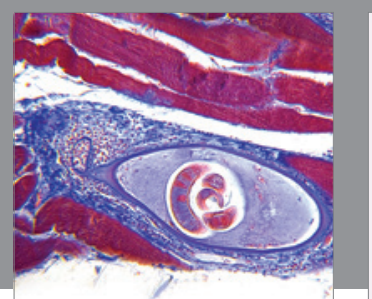

Gastroenterology Research and Practice

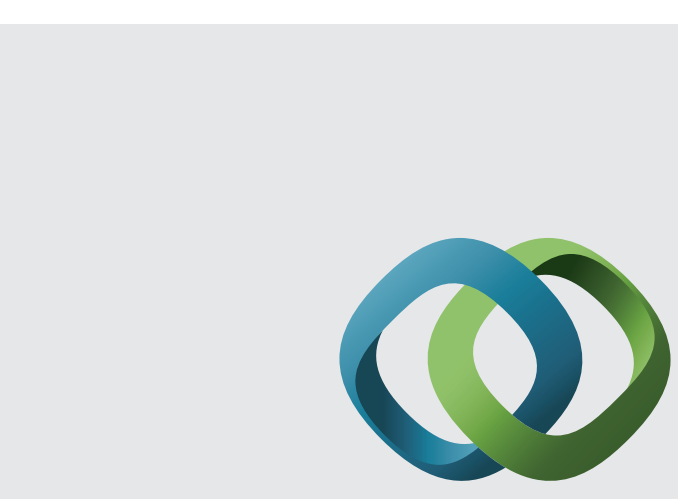

\section{Hindawi}

Submit your manuscripts at

http://www.hindawi.com
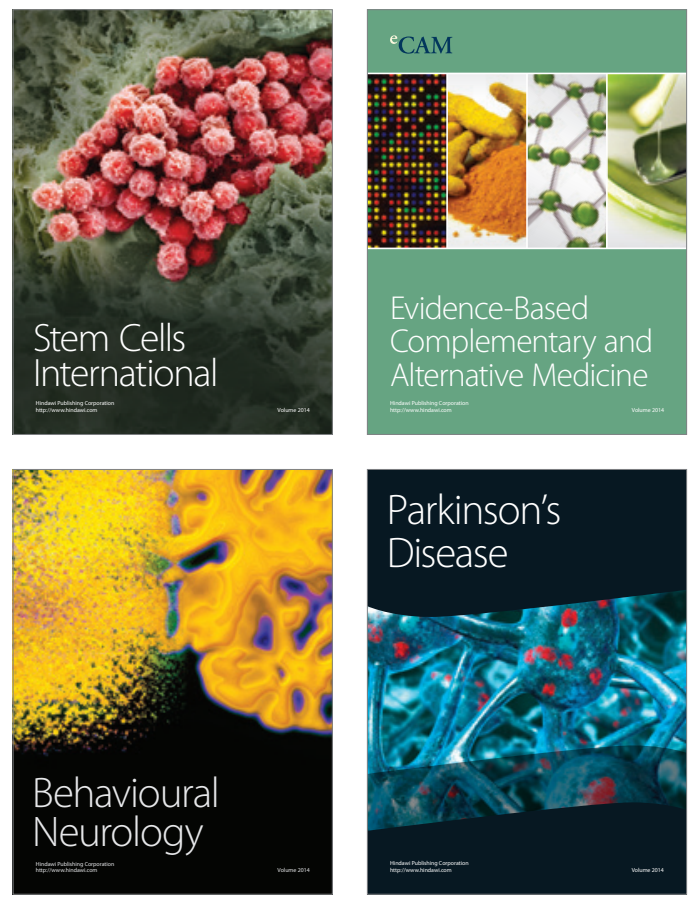
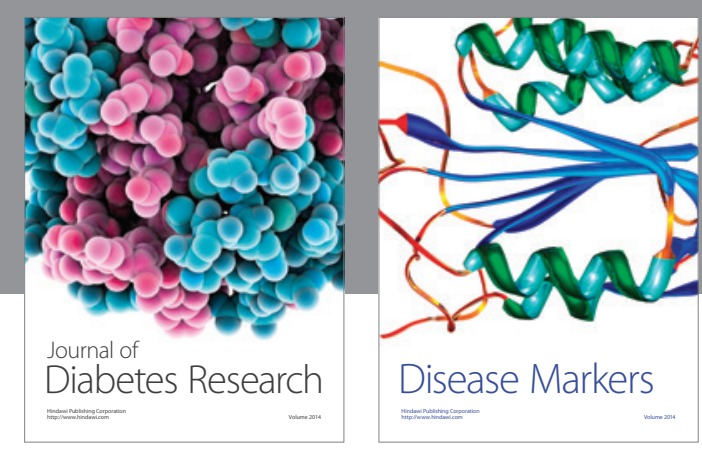

Disease Markers
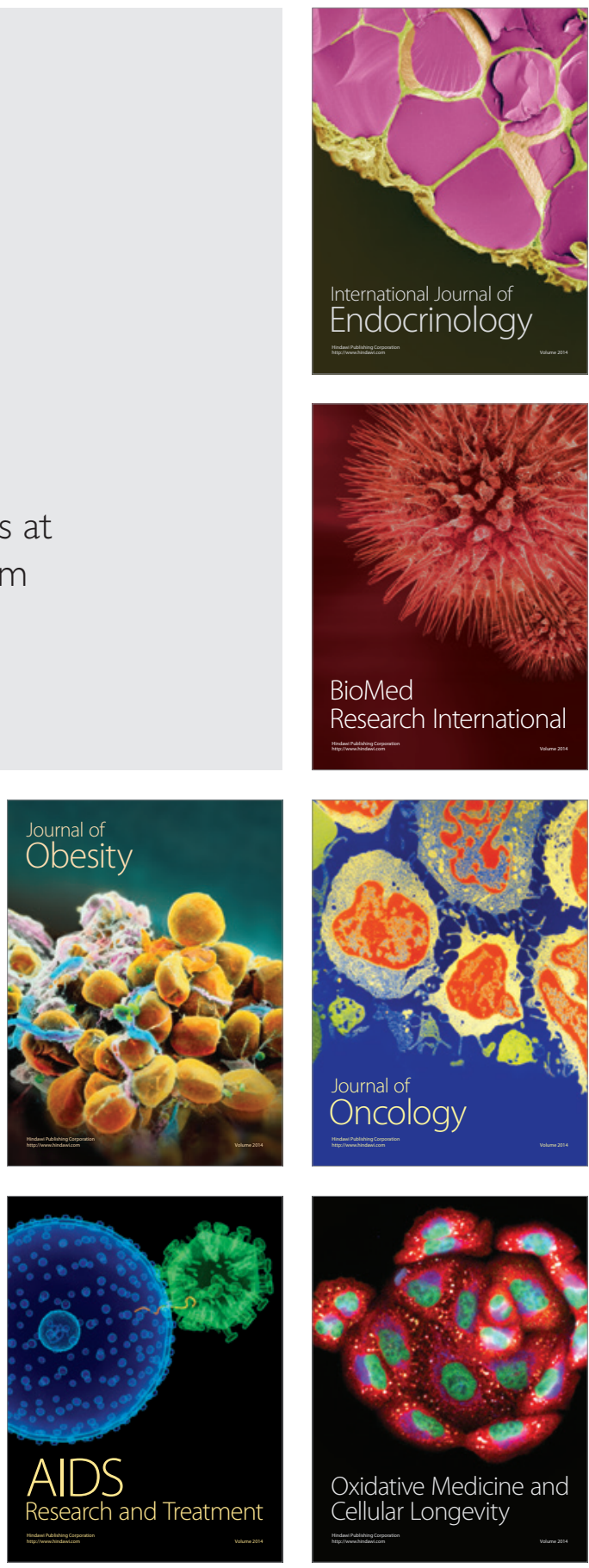